\title{
ASSOCIATION OF EPSTEIN-BARR VIRUS (EBV) BUT NOT HUMAN PAPILLOMAVIRUS (HPV) WITH GINGIVITIS AND/OR PERIODONTITIS IN TRANSPLANTED INDIVIDUALS
}

\author{
Camila Freze BAEZ(1), Flavia SAVASSI-RIBAS(2), Wilker Menezes da ROCHA(2), Stéphanie G. S. ALMEIDA(2), Marianna T. V. GONÇALVES(2), \\ Maria Angelica A. M. GUIMARÃES(1), Silvia Maria B. CAVALCANTI(2) \& Rafael B. VARELLA(2)
}

\begin{abstract}
SUMMARY
The aim of this study was to investigate the association of EBV and HPV with gingivitis and/or periodontitis according to the immunologic status. To this end, 74 oral biopsies from transplanted and non-transplanted individuals with the abovementioned oral manifestations were submitted to a screening by PCR for both viruses. According to the results, EBV was strongly associated with gingivitis and/or periodontitis in transplanted individuals $(p=0.011)$ but not HPV $(p=0.766)$. EBV-HPV co-detections did not enhance the presence of tissue injury as well. Although a causal relationship was not investigated in this study, the higher frequency of these two oncoviruses in lesion tissues must be investigated in follow-up studies, especially among immunocompromised individuals.
\end{abstract}

KEYWORDS: HPV; EBV; Oral cavity; Kidney transplant.

Some viral agents have been associated with the pathogenesis of oral lesions in immunocompetent and immunosuppressed individuals, especially DNA viruses such as papillomaviruses and herpesviruses ${ }^{1}$. It has been postulated that the latter group triggers tissue damage which is further increased by the host inflammatory response ${ }^{2}$, creating an enabling an environment for the replication/reactivation of viral agents that may contribute to the pathogenesis of oral lesions ${ }^{3}$. However, the effect of the viral association in tissue damage is uncertain. Therefore, the aim of this study was to investigate the occurrence and association of two epitheliothropic agents from different viral families, namely Epstein-Barr virus (EBV) and Human papillomavirus (HPV), with gingivitis and/or periodontitis, according to the immunologic status.

This study included kidney transplant (Tx) patients and nontransplanted individuals (non-Tx), both with gingivitis and/or periodontitis, who attended the Dentistry School of Rio de Janeiro State University from 2005 to 2007. Periodontitis was classified as "chronic periodontitis", whereas gingivitis was classified as "dental plaque-induced gingivitis" ${ }^{4}$. Tx patients were under immunosuppressive therapy based on tacrolimus or cyclosporine. Patients that had been submitted to previous periodontal treatment, edentulous, smokers, and immunosuppressed patients other than the kidney transplant ones were excluded from the study. Sample biopsies were collected through periodontal surgery, according to aesthetic, functional and prosthetic needs, after the basic periodontal therapy.

Of the 74 oral biopsies collected, 60 samples from Tx patients were screened for HPV. However, due to sample constrains, only $40 \mathrm{Tx}$ biopsies were analyzed for EBV. Fourteen tissue samples from non-Tx individuals were also analyzed for both viruses. Viral detections were performed according to conditions previously described ${ }^{5,6}$. In order to guarantee the integrity of the extracted DNA, the beta-globin gene was tested in all the samples ${ }^{7}$. Statistical analyses were performed using the SPSS program for Windows, version 21 . The study was approved by the Ethics Committee of the College of Medicine from the Universidade Federal Fluminense (protocol no. 1138/2005).

Table 1 shows the correlation between the viral detection according to transplantation and tissue injury. EBV was associated with gingivitis and/ or periodontitis in oral tissue, in transplanted individuals $(p=0.011)$, but not HPV ( $p=0.766)$. Although EBV-HPV co-detection was significant in the lesions, the statistical analysis resulted in a higher $\mathrm{p}$-value than that found for EBV infection alone ( $p=0.048$ vs. 0.011 , respectively), indicating that such association is unlikely to be an enhancement factor of tissue lesions and suggests that only EBV is in fact related to the lesions. Tx and non-Tx groups did not differ statistically in terms of gender ( $p=$ $0.368)$ and age $(p=0.097)$ (data not shown).

Periodontal diseases as gingivitis and periodontitis are inflammatory processes resulting from periopathogenic bacterial and viral infections, environmental and host response interactions ${ }^{8,9}$. Among the most frequently searched viruses in periodontal sites are EBV and cytomegalovirus (CMV). In our study, we found an overall prevalence of $35.2 \%$ of EBV in tissue biopsies from gingivitis and periodontitis, which is compatible

(1) Universidade Federal do Rio do Janeiro, Department of Preventive Medicine, Hospital Universitário Clementino Fraga Filho. Rio de Janeiro, RJ, Brazil.

(2) Universidade Federal Fluminense, Department of Microbiology and Parasitology. Niterói, RJ, Brazil.

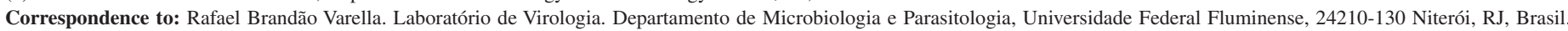
E-mail: rvarella@id.uff.br 
Baez CF, Savassi-Ribas F, Rocha WM, Almeida SGS, Gonçalves MTV, Guimarães MAAM, Cavalcanti SMB, Varella RB. Association of Epstein-Barr virus (EBV) but not human papillomavirus (HPV) with gingivitis and/or periodontitis in transplanted individuals. Rev Inst Med Trop Sao Paulo. 2016;58:58.

Table 1

Detection of HPV and EBV in periodontitis and/or gingivitis of Tx and non-Tx individuals

\begin{tabular}{|c|c|c|c|c|c|}
\hline Variable & $\begin{array}{c}\text { Category } \\
(+ \text { or }-)\end{array}$ & $\begin{array}{c}\mathbf{T x} \\
\mathbf{n}(\%)\end{array}$ & $\begin{array}{l}\text { Non-Tx } \\
\mathbf{n}(\%)\end{array}$ & Prevalence $(\%)$ & $p$ value $^{1}$ \\
\hline HPV (n=74) & $\begin{array}{l}+ \\
- \\
\end{array}$ & $\begin{array}{l}26(43.3) \\
34(56.7) \\
\end{array}$ & $\begin{array}{l}5(35.7) \\
9(64.3) \\
\end{array}$ & 41.9 & 0.766 \\
\hline $\operatorname{EBV}(n=54)$ & $\begin{array}{l}+ \\
-\end{array}$ & $\begin{array}{l}18(45) \\
22(55)\end{array}$ & $\begin{array}{c}1(7) \\
13(93)\end{array}$ & 35.2 & 0.011 \\
\hline HPV+EBV $(n=54)$ & $\begin{array}{l}+ \\
-\end{array}$ & $\begin{array}{l}10(25) \\
30(75)\end{array}$ & $\begin{array}{c}0 \\
14(100)\end{array}$ & 18.5 & 0.048 \\
\hline
\end{tabular}

HPV: Human papillomavirus; EBV: Epstein-Barr virus; Category: positive (+) or negative (-) samples for the tested virus; Tx: transplanted patients; Non-Tx: nontransplanted individuals; ${ }^{1} \chi^{2}$ test or Fisher exact test.Statistical significant results $(p<.05)$ are in bold letter.

to the described prevalence in the literature ${ }^{10}$. A recent study has failed to detect EBV in saliva from HIV-infected children with gingivitis in Brazil ${ }^{2}$. However, it is known that several factors can influence the viral detection in periodontitis, including the sample type, methodological approaches and geographical/ethnical differences regarding the herpesviruses occurrence $^{10}$. Moreover, herpesviruses were found in association with oral ulcerations after transplantation. Van der Beek et al. ${ }^{11}$ described the presence of EBV DNA in $24 \%$ of stem cell-transplanted patients with oral ulcerations. This frequency is compatible with the hereby described, despite originating from different patients with other oral lesions. Hence, the EBV involvement with different oral lesions after transplantation deserves further studies.

Another important virus associated with oral lesions, especially precancerous and cancers from the oropharynx and the oral cavity, is HPV. It has been demonstrated that HPV can infect periodontal pocket basal cells. Additionally, the chronic inflammation in periodontitis and gingivitis could favor the HPV persistence and replication, serving as a reservoir of HPV in the oral cavity ${ }^{10}$. In this study, we found a HPV prevalence of $41.9 \%$ in lesion biopsy samples, but unrelated to transplantation. Association studies between HPV gingival infection and periodontitis are controversial. Jacob et al. ${ }^{13}$ studying healthy individuals with and without periodontal disease did not find any positive gingival tissue for HPV-16. These results were similar to those obtained by Horewicz et al. ${ }^{14}$, with no detection of HPV-16 in either periodontitis or gingivitis. Nevertheless, a recent study showed a slightly higher HPV prevalence (46\%) in gingival crevicular fluid of HIV-positive adults, being HPV-6 and HPV-11 the only two genotypes found ${ }^{15}$.

In regard to the association of EBV with oral lesions in Tx patients, it seems that the functional impairment of $\mathrm{T}$ cell surveillance induced by the immunosuppressive treatment is the main driver of viral reactivation, as observed in other EBV-induced diseases ${ }^{16}$. Therefore, it's possible that EBV could induce tissue lesion in an immune permissive environment ${ }^{9}$, although other uninvestigated agents/factors might be involved. HPV is also benefited by immunosupression, and is associated with more aggressive forms of tumors in transplant recipients ${ }^{17}$. The lack of association between transplantation and oral lesions indicate that HPV is not involved in the pathogenesis of non-papillomatous oral injuries or is not enhanced by immunosupression in this particular clinical manifestation.

In conclusion, we observed a significant correlation between an oncogenic epitheliothropic agent, the EBV, with mucosal lesions in Tx individuals. Although frequently found in oral tissue, the same observation was not valid for HPV. Being persistent agents, papillomaviruses and herpesviruses should be monitored in longitudinal studies in order to observe their long term effects in the host, especially in immunocompromised individuals.

\section{REFERENCES}

1. Jakovljevic A, Andric M, Knezevic A, Soldatovic I, Nikolic N, Karalic D, et al. Human Cytomegalovirus and Epstein-Barr virus genotypes in apical periodontitis lesions. J Endod. 2015;41:1847-51

2. Otero RA, Nascimento FN, Souza IP, Silva RC, Lima RS, Robaina TF, et al. Lack of association between herpesvirus detection in saliva and gingivitis in HIV-infected children. Rev Inst Med Trop Sao Paulo. 2015;57:221-5.

3. Slots J. Herpesviral-bacterial interactions in periodontal diseases. Periodontol 2000. 2010;52:117-40

4. Armitage GC. Development of a classification system for periodontal diseases and conditions. Ann Periodontol. 1999;4:1-6.

5. Afonso LA, Moyses N, Alves G, Ornellas AA, Passos MR, Oliveira LH, et al. Prevalence of human papillomavirus and Epstein-Barr virus DNA in penile cancer cases from Brazil. Mem Inst Oswaldo Cruz. 2012;107:18-23.

6. Shotelersuk K, Khorprasert C, Sakdikul S, Pornthanakasem W, Voravud N, Mutirangura A. Epstein-Barr virus DNA in serum/plasma as a tumor marker for nasopharyngeal cancer. Clin Cancer Res. 2000;6:1046-51.

7. Kassem A, Technau K, Kurz AK, Pantulu D, Löning M, Kayser G, et al. Merkel cell polyomavirus sequences are frequently detected in nonmelanoma skin cancer of immunosuppressed patients. Int J Cancer. 2009;125:356-61.

8. Hernández M, Dutzan N, García-Sesnich J, Abusleme L, Dezerega A, Silva N, et al. Host-pathogen interactions in progressive chronic periodontitis. J Dent Res. 2011;90:1164-70.

9. Silva N, Abusleme L, Bravo D, Dutzan N, Garcia-Sesnich J, Vernal R, et al. Host response mechanisms in periodontal diseases. J Appl Oral Sci. 2015;23:329-55.

10. Slots J. Human viruses in periodontitis. Periodontol 2000. 2010;53:89-110.

11. van der Beek MT, Laheij AM, Raber-Durlacher JE, von dem Borne PA, Wolterbeek R, van der Blij-de Brouwer CS, et al. Viral loads and antiviral resistance of herpesviruses and oral ulcerations in hematopoietic stem cell transplant recipients. Bone Marrow Transplant. 2012;47:1222-8. 


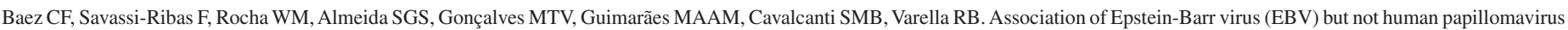
(HPV) with gingivitis and/or periodontitis in transplanted individuals. Rev Inst Med Trop Sao Paulo. 2016;58:58.

12. Hormia M, Willberg J, Ruokonen H, Syrjanen S. Marginal periodontium as a potential reservoir of human papillomavirus in oral mucosa. J Periodontol. 2005;76:358-63.

13. Jacob A, Janam P, Vijayamma JM. Prevalence of human papilloma virus in marginal periodontum and its association with periodontitis: a cross sectional study. J Indian Soc Periodontol. 2014;18:447-50.

14. Horewicz VV, Feres M, Rapp GE, Yasuda V, Cury PR. Human papillomavirus-16 prevalence in gingival tissue and its association with periodontal destruction: a case control study. J Periodontol. 2010;81:562-8.
15. Escalona L, Correnti M, Veitía D, Perrone M. Detección de virus papiloma humano en el fluido gingival de pacientes con inmunodeficiencia humana y enfermedad periodontal. Invest Clin. 2011;52:207-15.

16. Mertz KD, Pfaltz M, Junt T, Schmid M, Fernandez Figueras MT, Pfaltz K, et al Merkel cell polyomavirus is present in common warts and carcinoma in situ of the skin. Hum Pathol. 2010;41:1369-79.

17. Reusser NM, Downing C, Guidry J, Tyring SK. HPV carcinomas in immunocompromised patients. J Clin Med. 2015:4:260-81.

Received: 27 October 2015

Accepted: 22 February 2016 